crop and its pests and their natural enemies will allow us to grow perfect crops naturally? Will the techniques of biotechnology help us to outwit the pests and develop crops that fix their own N?

For an assessment of what lies ahead, five experienced scientists discuss, in the areas of weed control, insect management, disease management, and fertilizer practices, the possible strategies that may minimize use of synthetic fertilizers and pesticides.

\section{Literature Cited}

Casagrandc, R.A. 1987. The Colorado potato beetle: 125 years of mismanagement. Bul. Entomol. Sot. Amer. p. 142-150.

EPA. 1988. Status of chemicals in special review program. Registration standards program, fiscal year 1987 report. Environmental Protection Agency, Washington, D.C.

Thompson, H.C. and W.C. Kelly. 1957. Vegetable crops. McGraw Hill, New York. p. 52.

\title{
Vegetable Weed Control with Minimal Herbicide Inputs
}

\author{
A.R. Putnam \\ Department of Horticulture and Pesticide Research Center, Michigan State University East Lansing, MI 48824
}

Numerous concerns among the general public and farm community have provided a renewed interest in methods for growing crops with fewer inputs of energy and chemicals and for renewed efforts to conserve soil and water resources. Pest control researchers have long realized that heavy reliance on one control strategy produces adapted pest populations that may evolve to become more troublesome than the previous generations. Therefore, there is a need to develop and implement sustainable systems that integrate biological, cultural, mechanical, and chemical strategies. To be acceptable, these systems should be economic in both the short and long term. As usual, the vegetable grower finds him or herself in a squeeze; this time, between concern for protection of the environment and the production of residue-free produce and economics, i.e., how to do this with reduced chemical input and still make a profit? The major reason for using herbicides, in the first place, was to replace expensive and often difficult-to-find labor that was required for weed control.

There are several alternative strategies available for weed control, although their effectiveness varies from region to region. The focus of this paper is on methods that growers can now employ to reduce herbicide inputs in vegetable production.

\section{BIOLOGICAL CONTROL}

The biological approach is to use another organism (a natural enemy or introduced organism) that becomes established in high enough populations to greatly reduce the weed's growth, competitive ability, or population density. In vegetable crop production, this approach is still in the research rather than the application stage. However, the approach has worked successfully in other cropping systems and in rangelands (Cullen et al., 1973; Daniel et al., 1973; Trujello, 1985; Woodhead, 1981). In recent years, research has focused on species-specific insects, fungi, or nematodes that can control weeds without attacking crops. The best results have been obtained with plant pathogenic fungi that are sprayed on the weeds. These "mycoherbicides" have worked particularly well in the southeastern United States, where temperatures and humidify are more favorable for their development than in drier climates (Daniel et al., 1983; Woodhead, 1981). Particularly noteworthy for vegetables are the promising results obtained by Phatak et al. (1983) on nutsedges with Puccinia rust (Table 1). Using chemical approaches alone for control of nutsedges in vegetables generally has not been acceptable. Using the rust pathogen together with other strategies might provide better results. To perform effectively, these fungi must be protected from exposure to broad-spectrum fungicides that are sometimes used for vegetable disease control. Although biocontrol agents may be particularly useful for reducing certain noxious weed species, it must be remembered that once the former is removed, other weeds will quickly fill the vacated niche, thus presenting a new challenge to the grower. Biological weed control agents, because of their environmental safety, will undoubtedly receive more research attention. Many fungi now look promising for

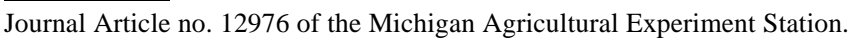

controlling problem weeds that affect vegetables. However, because of the limitations imposed on their effectiveness by the environment, difficulty in integrating with other methods, and recognition that new weed pests will quickly fill the niche, biocontrol by itself will not provide a utopia.

\section{CULTURAL CONTROL}

This approach includes any manipulation of crops or their culture that can provide weed suppression. Vegetable growers in all parts of the world have used cultural approaches for centuries without an understanding of the science behind their success. "Smother crops" are an example of a cultural practice that is widely used to reduce weed populations. Cereal grains, buckwheat, and sorghum $\times$ sudangrass hybrids are examples of effective smother crops. These crops are quickly established and usurp the resources that weeds would otherwise use. Many are believed to suppress weeds through

Table 1. Effect of rust fungus on nutsedge tuber formation and survival 120 days after rust release (adapted from Phatak et al., 1983).

\begin{tabular}{lcc}
\hline \hline & \multicolumn{2}{c}{ No./m ${ }^{2}(120$ days $)$} \\
\cline { 2 - 3 } Nutsedge & Rust-infected & Control $^{2}$ \\
\hline Tubers & 180 & 117 \\
Old & 17 & 68 \\
New & & \\
Plants & 155 & 338 \\
Live & 132 & 6 \\
Dead & & \\
\hline
\end{tabular}

'Weekly application of chlorothalonil.

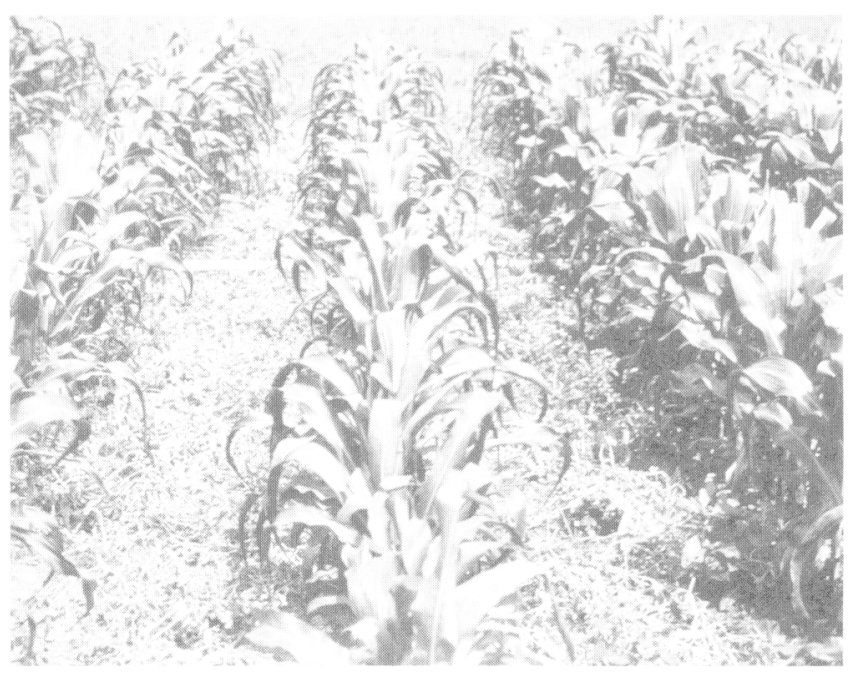

Fig. 1. Relay cropping system using peas interplanted with sweet corn. Pea vines remain as mulch to suppress weeds in corn. 
both competition (resources) and allelopathy (chemical influences) (Overland, 1966).

Crop cultivars vary greatly in their ability to interfere with weeds. I remember as a youth that New England vegetable growers used 'Green Mountain' potatoes, which, after hilling, formed a dense mat of vines that shaded out the weeds. There are a few scientific studies comparing competitive abilities of crop germplasm (Sweet, 1974), but little has been done to search for highly competitive types grown in "weedy" cultures. At least one extension bulletin suggests the use of competitive cultivars as a weed control strategy (Ellerbrock, 1987). Many intercropping or relay cropping systems that are used by subsistence farmers in developing countries employ the principle that space should be occupied by crops, not weeds. Relay cropping could easily be employed by market gardeners who harvest their crops by hand. These crops should be planted in such away that the intercrop provides an effective canopy to shade weeds or that the previous crop residue can be used as a mulch to prevent weed growth in the successional crop. In test plots, we have used peas as early interplants where sweet corn and tomatoes are to be planted later (Fig. 1). The pea vines are left as mulch after harvest in early July. We have also used cool-season Brassicas as interplants in longer-season vegetables with good success (Fig. 2).

A promising cultural approach that is gaining acceptance by vegetable growers is the use of cover crops that provide attributes of a smother crop, but residues of which also have allelopathic effects on weeds. One of the most effective plants for this use is rye (Secale cereale L.) (Barnes and Putnam, 1983, 1987). Residues of rye, if left on the soil surface, release chemicals that are extremely inhibitory to seedling growth of many annual dicotyledonous weeds (Table 2, Fig. 3). Response of grassy weeds to these residues is generally more variable. The rye may be killed chemically with nonselective herbicides (glyphosate, glufosinate, or paraquat), with selective graminicides (fluazifop or sethoxydim), or, if mature enough, it may be mechanically chopped before crop emergence or transplanting. Additional benefits of the cover crop's residues are soil and water conservation and protection from wind damage. Some growers use strip tillage in narrow bands where the crop is to be planted. Although this sometimes provides better crop growth, the soil disturbance aggravates the weed problem in the band. In tomatoes, excellent results have been obtained by using the rye cover crop approach for early season weed control, followed by one application of metribuzin at $0.28 \mathrm{~kg} \cdot \mathrm{ha}^{-1}$ for later-season weeds.

Crops could conceivably be genetically manipulated to produce more competitive cultivars. Greater interference capability against weeds could be achieved through either allelopathy or an improved capability to compete for resources, or both. A screening of the world's cucumber germplasm (Putnam and Duke, 1974), revealed accessions that demonstrated allelopathic potential (Table 3). PI

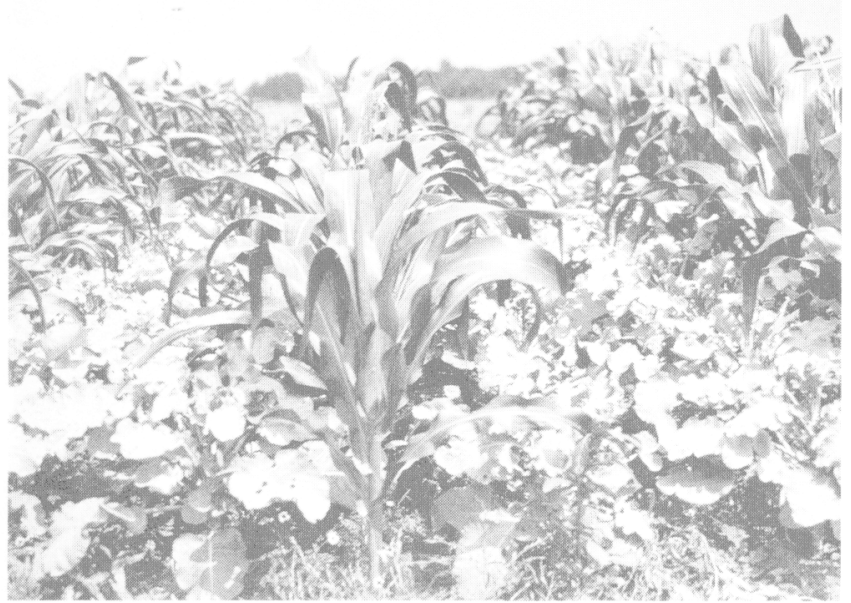

Fig. 2. Broccoli intercropped with sweet corn. Broccoli planted at high density forms a canopy to shade weeds in the early season.
169391 was particularly effective in laboratory and field studies (Lockerman and Putnam, 1979). This has also been found within other important crops (Fay and Duke, 1977; Leather, 1983; Overland, 1966). Although germplasm with these attributes has been identified, I am aware of no effort to manipulate plants genetically for competitive advantage over weeds. Since several species of weeds can form virtual monoculture by these same mechanisms, it would seem that the idea is viable.

Vegetable crops can better interfere with weed growth if they are planted in configurations that allow them to more effectively usurp resources. If crops can reduce incident light by $50 \%$ or more, weeds will seldom become a problem (Sweet, 1974). This approach usually requires closer row spacings and higher densities than commonly used. In a sense, this method becomes a gamble for the grower, because planting in these configurations may eliminate the ability to cultivate the crop mechanically. Combining the cover crop approach previously mentioned with high-density planting does lower

Table 2. Weed suppression with surface residues of rye compared with Populus wood shavings (from Putnam and DeFrank, 1983).

\begin{tabular}{lc}
\hline \hline Residue & Weed fresh wt $(\mathrm{g})$ \\
\hline Populus wood shavings & 224 \\
Rye & 81 \\
Control & 398 \\
LSD at $P=0.05$ & 65 \\
\hline
\end{tabular}
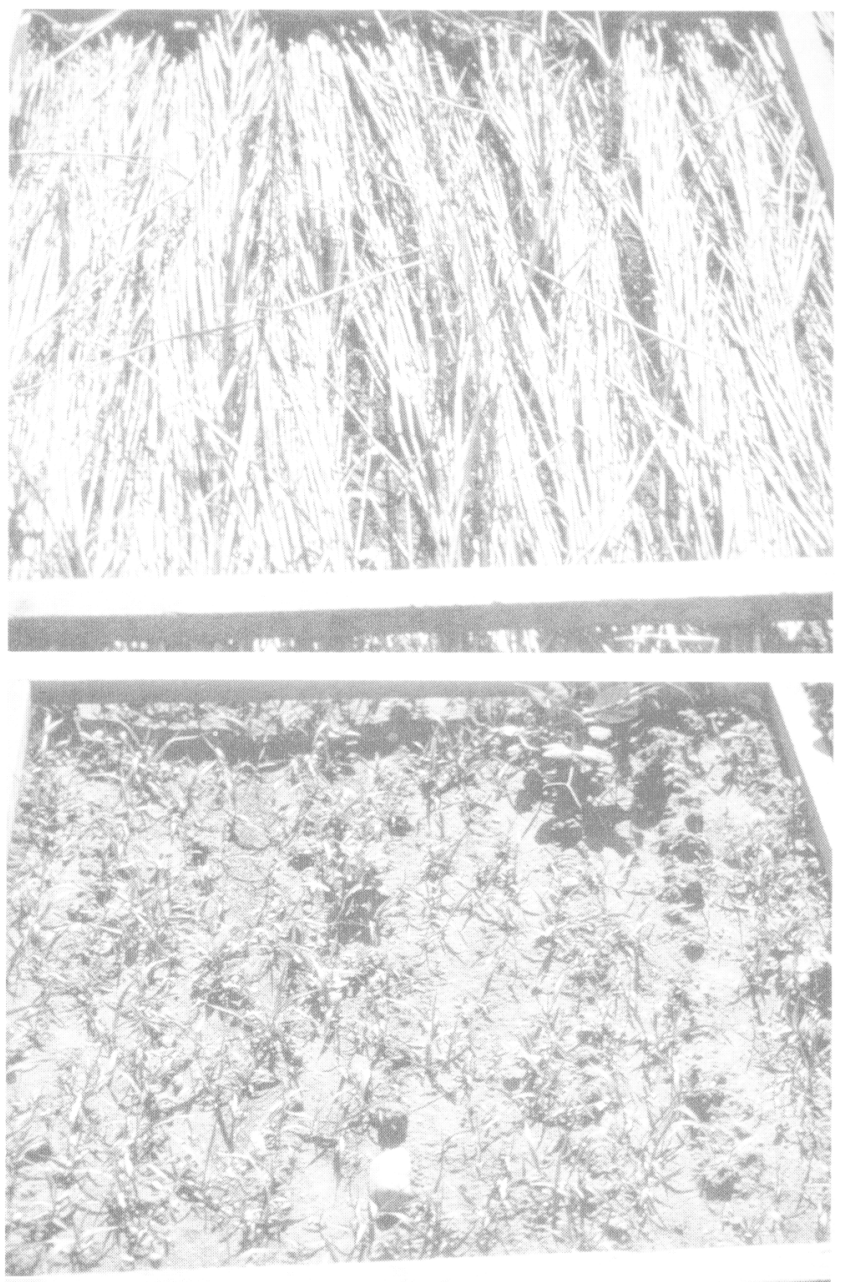

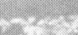

Fig. 3. (top) Suppression of annual weeds with rye residues; (bottom) control plots also received glyphosate spray 30 days before date of photograph. 
Table 3. Average weed weights and vine weights of a cucumber cultivar and two plant introductions grown in association with weeds (from Lockerman and Putnam, 1979).

\begin{tabular}{lccr}
\hline \hline $\begin{array}{l}\text { Accession or } \\
\text { cultivar }\end{array}$ & \multicolumn{2}{c}{ Mean cucumber vine wt $(\mathrm{g})$} & \\
\cline { 2 - 3 } & Weeded & Nonweeded & $\begin{array}{c}\text { Total weed } \\
\text { wt }(\mathrm{g})\end{array}$ \\
\hline No cucumber & --- & --- & $10.4 \mathrm{a}$ \\
Pioneer & $361 \mathrm{a}$ & $234 \mathrm{C}$ & $4.9 \mathrm{~b}$ \\
PI 169391 & $358 \mathrm{a}$ & $274 \mathrm{~b}$ & $1.7 \mathrm{c}$ \\
PI 285605 & $378 \mathrm{a}$ & $214 \mathrm{C}$ & $3.6 \mathrm{~b}$ \\
\hline
\end{tabular}

the risk. For example, early weed control obtained with rye residues provides time for crops, such as cucumber and snap beans, to establish a canopy that effectively suppresses the later-emerging weeds. Development of highly active postemergent herbicides does allow "rescue" treatment if the natural mechanisms fail to provide satisfactory control.

Another cultural approach involves the use of rotational crops other than vegetables on a portion of the hectarage. One may choose to include crops with either greatly different cultural practices or with perennial habit that will upset the life cycle of the weeds. For example, many California vegetable growers put a troublesome weedy field through an alfalfa rotation to help reduce weed problems.

\section{MECHANICAL CONTROL}

This broad category of strategies includes any approach involving the use of mechanical or human energy. Weed scientists have traditionally included hand-pulling, hoeing, machine-powered tillage, mowing, flooding, and mulching under-this category. The use of hand labor for weed control in the United States is now generally unpopular because of excessive costs. However, there certainly can still be economic benefit in roguing occasional weeds from fields and preventing them from producing tens or hundreds of thousands of seed per plant. This might require only 2 to 4 hours of labor per hectare. Herbicides have almost completely replaced hand labor because their cost to the farmer may be only $1 / 5$ th to $1 / 20$ th as great. In addition, it has been difficult to find anyone other than migrant farm labor or children who are willing to perform this tedious work.

Tillage is still a widely used method of weed control. A variety of specialized took that cut, lift, or bury weeds have been developed. Particularly popular among vegetable growers are rolling types of cultivators that allow shallow cultivation and that accommodate a variety of row spacings and configurations. Tillage is often integrated with herbicides; in fact, several of the herbicides have to be incorporated with tillage equipment to prevent volatilization or photodegradation. The disadvantages of prolonged tillage are impaired soil structure and increased soil compaction. Many tilled sites are subject to severe soil erosion, with losses in excess of 11,000 $\mathrm{kg} \cdot \mathrm{ha}^{-1}$ being common. Seldom has soil loss been figured into the long-term economics of farming. With an $11,000 \mathrm{~kg} \cdot \mathrm{ha}^{-1}$ loss of soil per year, the loss in just nutrients alone represents an additional $\$ 62 /$ ha in fertilizer. Each cultivation also brings new weed seeds to the surface, where they have suitable conditions for germination. On the other hand, tillage is economical and provides effective control of perennial weeds because many propagules are cut and brought to the soil surface, where they will be desiccated or frozen. One of the major problems in no-tillage or minimum tillage systems is an increase in perennial weed problems.

Mulches are another mechanical strategy with good utility for the vegetable grower. Mulches, which come in either natural form (as plant residues) or in synthetic form as plastic films or woven synthetic fibers, kill weeds by excluding light and by forming a physical barrier to growth. Both organic and synthetic mulches are widely used by home gardeners. Commercial vegetable growers now extensively use plastic films for weed control and to warm the soil for transplanted crops. The major disadvantages of plastic films are material costs and the difficulty in removing the material from the field at the end of the season. There is extensive research being carried out now on more degradable types of films for use in weed control. Growing organic mulches in place and allowing them to exist in low vigor (living mulches) or as allelopathic residues may provide an economical alternative to synthetic mulches, although they may slightly cool, rather than warm, the soil.

Mowing is an effective method of preventing seed production in field margins. From this standpoint, it fits better under prevention than control. Vegetable farmers that have achieved low weed seed populations have often done so by combining extensive mowing in non-crop areas and roguing weeds within the fields before they produce seed.

Short-term flooding has been used to a limited extent to control established vegetation. This practice is still used in many areas where the terrain lends itself to flooding or where rice fits into the cropping sequence. On the negative side, flooding also introduces many weed propagules, so, over the long-term, it may exacerbate the weed problem.

\section{REDUCING HERBICIDE INPUTS}

The "proper" rate of herbicide application is indicated on all product labels and is also included in recommendations produced by the Cooperative Extension Service. Proper rates are really based on averages that industrial and university scientists have determined should work a high percentage of the time for the grower. They are provided with the idea that the least product liability (non-performance or crop damage) should occur with those rates. They are also provided by the manufacturer with the idea of selling enough chemical to cover development costs. University investigators have been interested in developing guidelines for use of reduced (lower-thanlabeled) rates of pesticides (Baldwin et al., 1987; Chase et al., 1987).

The EPA does allow recommendations for reduced rates if the investigator has data to support these recommendations. It is wellknown that, with proper timing and selected application methods, good control can be achieved with one-fourth to one-half rates of application. Why should we be interested in reduced rates? The reasons are obvious. Herbicides are becoming more expensive and profit margins on many crops are small. By putting less pesticide into the environment, we reduce the risk of contamination and adverse side effects. Growers, environmentalists, researchers, and the general population would all prefer that less pesticides be used.

\section{Banded applications of herbicides}

Many growers save chemical costs by simply banding their herbicide in a strip 15 to $30 \mathrm{~cm}$ wide along the crop row. Weeds between the rows are controlled with cultivation. The herbicide controls weeds in the area where early competition might be critical and eliminates the need for hand weeding or hoeing where disturbance might damage crop seedlings. Savings are proportional to the reduction in area sprayed. This technique can also reduce environmental impact.

\section{Use of low volumes to improve glyphosate performance}

Recent research has shown that glyphosate gives better control of many weeds, as well as improved knockdown of cover crops, when it is applied in lower volumes of water per hectare (Table 4).

Table 4. Quackgrass control and rye kill with glyphosate at various rates and spray volumes (liters·ha') (from Chase et al., 1986).

\begin{tabular}{|c|c|c|c|}
\hline \multirow{3}{*}{$\begin{array}{l}\text { Glyphosate rate } \\
\left(\mathrm{kg} \cdot \mathrm{ha}^{-1}\right)\end{array}$} & \multicolumn{3}{|c|}{ Control rating $^{2}$} \\
\hline & \multicolumn{3}{|c|}{ Volume applied (liters $\cdot \mathrm{ha}^{-1}$ ) } \\
\hline & 300 & 166 & 83 \\
\hline \multicolumn{4}{|l|}{ Quackgrass } \\
\hline 0.55 & 4.8 & 6.0 & 7.3 \\
\hline 0.82 & 6.5 & 6.8 & 9.3 \\
\hline 0.1 .1 & 7.5 & 7.5 & 9.8 \\
\hline Rye & 300 & 124 & 83 \\
\hline 0.18 & 1.8 & 5.3 & 6.5 \\
\hline 0.37 & 6.0 & 10.0 & 10.0 \\
\hline 0.75 & 10.0 & 10.0 & 10.0 \\
\hline
\end{tabular}

${ }^{\mathrm{z}} 0=$ No weed control, $10=$ complete weed control. 
Table 5. Control of several early season weeds in muckland onions with Iower-than-registered rates of postemergencc herbicides. ${ }^{2}$ (Experiment conducted by B.H. Zandstra and T. Wallace; from Chase et al., 1987.)

\begin{tabular}{|c|c|c|c|c|c|c|c|c|}
\hline Herbicide & $\begin{array}{c}\text { Rate } \\
\left(\mathrm{g} \cdot \mathrm{ha}^{-1}\right)\end{array}$ & $\begin{array}{c}\text { Large } \\
\text { crabgrass }\end{array}$ & $\begin{array}{c}\text { Common } \\
\text { lambsquarters }\end{array}$ & $\begin{array}{l}\text { Common } \\
\text { purslane }\end{array}$ & Ladysthumb & $\begin{array}{c}\text { Prostrate } \\
\text { knotweed }\end{array}$ & $\begin{array}{l}\text { Prostrate } \\
\text { pigweed }\end{array}$ & $\begin{array}{l}\text { Redroot } \\
\text { pigweed }\end{array}$ \\
\hline \multirow[t]{2}{*}{ Oxyfluorfen } & 35 & 9.0 & 10.0 & 8.3 & 6.7 & 6.7 & 10.0 & 10.0 \\
\hline & 70 & 8.3 & 10.0 & 9.0 & 7.3 & 8.3 & 10.0 & 10.0 \\
\hline \multirow[t]{2}{*}{ Bromoxynil } & 70 & 4.0 & 10.0 & 2.3 & 8.3 & 10.0 & 6.0 & 9.3 \\
\hline & 140 & 4.0 & 10.0 & 2.7 & 9.7 & 10.0 & 7.0 & 9.3 \\
\hline
\end{tabular}

${ }^{2}$ Experiment kept weed-free with $35 \mathrm{~g}$ oxyfluorfen $+112 \mathrm{~g}$ fluazifop/ha for the rest of season.

In effect, this provides a spray of higher concentration, but less total chemical applied per hectare. Our own research has shown that quackgrass can be controlled as well with $0.82 \mathrm{~kg}$ glyphosate/ ha in $\approx 83$ liters of water/ha as with $1.1 \mathrm{~kg}$ in 300 liters of water (Chase et al., 1986). This reduces the cost of chemical by $50 \%$.

Where we have used rye as a winter cover crop and wish to maintain its residues on the surface in no-till cropping systems, we have also found that low spray volumes can reduce the herbicide rate required. In this case, effective kill of rye is achieved with 280 to $425 \mathrm{~g}$ of glyphosate/ha in 83 to 124 liters of water/ha (Table 4). In this system, herbicide cost may only represent $\$ 12.00$ to $\$ 18.50$ / ha (Chase et al.; 1986).

\section{Proper timing of postemergence herbicides}

Several researchers have discovered that "lower-than-labeled rates" of newer postemergence herbicides will do an effective job if careful attention is given to proper timing as related to weed size (Baldwin et al., 1987; Chase et al., 1986, 1987). In general, growers tend to wait until the weeds are too large. Herbicides that are effective for broadleaf weed control (e.g., bentazon, acifluorfen, oxyfluorfen) can be used at 0.25 to 0.50 rates if the weeds are sprayed at a very young ( $<2.5 \mathrm{~cm}$ tall) stage (Table 5$)$. A similar trend occurs with the postemergence grass killers fluazifop and sethoxydim. In the case of fluazifop, both -reduced volume and smaller weed size can result in substantial herbicide savings. Baldwin has done considerable work on low rates and has been a pioneer in recommending these to farmers (Baldwin et al., 1987).

\section{Use of herbicide combinations at low rates}

The principle here is to blend two or more herbicides at low rates and exploit the strengths of each on the particular weed species. A recent example is the finding that clomazone will control velvetleaf (Abutilon theophrasti Medik.) at rates of about one-fourth that required to kill many other weed species (Thelen et al., 1988). Where velvetleaf is a serious problem, blending of small amounts of this product could provide exceptional results. Use of low rates would also greatly reduce the potential for off-target problems with this herbicide. There are also selected herbicide combinations that are synergistic, i.e., the results are greater than expected from their additive effects.

\section{Use of newer, more-active chemicals}

The newer generations of pesticides contain much more activity per kilogram. In fact, several are now used at only a few grams per hectare. Some of the older pesticides, particularly herbicides, were used at several kilograms per hectare. When considering the total chemical load on the environment, it seems a better strategy to use the highly active and more rapidly degradable variety of chemical. Not only will they produce less environmental contamination, but there is less likelihood of residues persisting on the harvested food $\mathrm{p} \mathrm{r}$ o d u c t.

\section{Monitoring fields to achieve spray decisions}

Monitoring is an integral part of pest management programs. In the case of weeds, it is probable that an economic population will present itself in 99 out of 100 cases, whereas the frequency might be much lower with insect or disease pests. Nonetheless, monitoring can still provide important information regarding the nature of the populations. For example, certain problem species may be localized and only require spot treatments. In other instances, previous prac- tices may have effectively eliminated dicots, leaving grasses as the major problem needing postemergent treatments. The use of monitoring does allow use of more selective treatments rather than a "sledgehammer approach" to weed control.

\section{SUMMARY}

Numerous weed prevention and control strategies are available to the vegetable grower. Each has its particular set of advantages and disadvantages, and no one strategy can be successfully employed repeatedly without adaptation of [he weed flora. It will be difficult for the large, highly mechanized grower to eliminate herbicide use completely, but several options are available to reduce herbicide input. Smaller growers with specialized retail markets can probably afford to eliminate almost all herbicide use if they carefully integrate other methods and charge somewhat more for their products. A realistic objective should be to integrate biological, chemical, cultural, and mechanical tactics with the realization that approaches must be altered as weed populations adjust. To reduce herbicide input is a noble objective shared by researcher, grower, and the general public. To eliminate these chemicals altogether is not a realistic goal. The more-effective and safer chemicals will probably continue to be important components in the integrated weed control effort.

\section{Literature Cited}

Baldwin, F. L., T.N. Tripp, and L.R. Oliver. 1987. Minimum input weed control programs. Arkansas Coop. Ext. Serv. Circ. Soy 2-87.

Barnes, J.P. and A.R. Putnam. 1987. Role of benzoxazinones in allelopathy by rye (Secale cereale L.) J. Chem. Ecol. 13:889-906.

Barnes, J.P. and A.R. Putnam. 1983. Rye residues contribute weed suppression in no-tillage cropping systems. J. Chem. Ecol. 9: 1045-1057.

Chase, W. R., A.R. Putnam, B.H. Zandstra, E. Hanson, J. Hull, Jr., C. Peterson, and T. Wallace. 1986. Weed control field research in horticultural crops. Michigan State Univ. Hort. Rpt. 40:107.

Chase, W. R., A.R. Putnam, B.H. Zandstra, E. Hanson, J. Hull, Jr., K. Takahara, and T. Wallace, Jr. 1987. 1987 Weed control field research on horticultural crops. Michigan State Univ. Hort. Rpt. 42:81-82.

Cullen, J. M., P.F. Kablc, and M. Katt. 1973. Epidemic spread of a rust imported for biological control. Nature (London) 244:462-463.

Daniel, J. T., G.E. Templeton, R.J. Smith, and W.T. Fox. 1973. Biological control of northern jointvetch in rice with an endemic fungal disease. Weed Sci. 21:303-307.

Ellerbrock, L.A. 1987. Cornell recommendations for commercial vegetable production. Cornell Univ., Ithaca, N.Y.

Fay, P.K. and W.B. Duke. 1977. An assessment of allelopathic potential in Avena germplasm. Weed Sci. 22:224-228.

Leather, G.R. 1983. Sunflowers (Heianthus annus) arc allelopathic to weeds. Weed Sci. 31:37-42.

Lockerman, R.H. and A.R. Putnam. 1979. Field evaluation of allelopathic cucumbers as an aid to weed control. Weed Sci. 27:54-57.

Overland, L. 1966. The role of allelopathic substances in the "smother crop" barley. Amer. J. Bet. 53:423-427.

Phatak, S. C., D.R. Sumner, H.D. Wells, D.K. Bell, and N.C. Glaze. 1983. Biological control of yellow nutsedge with the indigenous rust fungus Puccinia canaliculata. Science 219:1446-1448.

Putnam, A.R. and J. DeFrank. 1983. Use of phytotoxic plant residues for selective weed control. Crop Proctect. 2:173-181.

Putnam, A.R. and W.B. Duke. 1974. Biological suppression of weeds: Evidence for allcelopathy in accessions of cucumber. Science 185:370372.

Sweet, R.S. 1974. Weed science research results. Dept. of Veg. Crops, Cornell Univ., Ithaca, N.Y.

Thelen, K. D., J.J. Kens, and D. Penner. 1988. Comparison of application 


\title{
Vegetable Insect Control with Minimal Use of Insecticides
}

\author{
John T. Trumble \\ Department of Entomology, University of California, Riverside, CA 92521
}

\section{RATIONALE FOR MINIMUM INSECTICIDE VEGETABLE PRODUCTION}

Large scale commercial vegetable producers rarely adopt minimum input or sustainable agricultural practices for altruistic reasons. While some family-owned concerns have followed this approach with the intent of passing their land onto the next generation in as pristine a state as possible, much of California's vegetable hectarage is managed by large corporations. Thus, development and implementation strategies using reduced pesticide input are less likely the result of environmental concerns and more likely due to economic incentives, legislation limiting pesticide use, or the development of significant levels of pesticide resistance.

In terms of pesticide use, the California vegetable industry is approaching a critical period. California's expanding urban population has led to an increase in the influence of environmental activists, labor unions, and other consumer groups that are increasingly vocal in their opposition to pesticides. In addition, the current senate and assembly, committees in California that deal with pesticides have few members with rural or agricultural backgrounds.

This situation has lead to an increase in legislation restricting pesticides. At least 26 new bills relevant to the subject were introduced in California in 1987 alone. Nearly all of these would require further restrictions on the use of chemicals for insect control. The impact of the new laws dealing with ground water contamination -and plant-back restrictions has dramatically changed pesticide use patterns in California; as a consequence, the application of persistent pesticides has declined appreciably. The impact of laws generated by referendum (placed on the ballot after proponents file the required number of signatures on petitions) is less well-defined. Such consumer-generated legislation provides evidence of the growing perception that consumers take the risk when pesticides are used, while growers reap the profits.

There also has been a resurgence in environmental concern by the general population. In the past few years, incidents of environmental concern at Love Canal and Kesterson Reservoir, as well as the tragic events at Bhopal, India, have been given considerable time on television. The publicity associated with the watermelon contamination incident in California and the recent National Academy of Sciences report (National Research Council, 1986) highlighting the potential for pesticidal contamination in vegetables, have brought this concern into nearly every household in the country. Our ability to find residues at the parts-per-trillion level has aggravated this problem. Many consumers do not recognize differences in risk levels between parts per hundred and parts per trillion, they only recognize that no level of risk is acceptable.

An additional stimulus for reduced insecticide use is the declining availability of efficacious insecticides. The rate of development of insecticide resistance is increasing exponentially (Georghiou, 1986). Nearly every entomologist study vegetable crop production can cite cases of extensive losses resulting from insecticide resistance. The \$20 million loss documented by California's celery industry in 1984 following the development of resistance by the leafminer [Liriomyza trifolii (Burgess) (Diptera: Agromyzidae)] to diverse chemicals provides an excellent example (California Celery Research Advisory Board, 1986). Thus, the need has been adequately demonstrated to the vegetable industry that a more-prudent approach would include a move toward less insecticide-intensive pest management practices.

\section{The search for new approaches}

Several new or rediscovered approaches to low insecticide input agriculture are being investigated. One approach receiving considerable attention is the use of new technology machinery. Electrostatic sprayers and controlled-droplet application devices offer help in reducing amounts of insecticides used in vegetable crop systems (Matthews, 1979), but, by themselves, will not provide a long-term solution to insecticide resistance. The recent development of a tractor-mounted suction unit that provides excellent control of Lygus spp. in strawberries (E. Show, Driscoll Corp., personal communication) offers considerable advantages over insecticide applications that cause resurgence in two-spotted spider mite populations (Tetranychus urticae Koch).

Many of the "new" techniques suggested for sustainable agriculture are simply improvements or recycling of approaches developed for integrated pest management (IPM) purposes. This recycling does not make these approaches less useful; in fact the sustained interest is helping to increase use. Moreover, IPM practices have become a mainstay for implementation of sustainable agriculture (Poincelot, 1986). Examples include use of polyester row covers for insect exclusion (Natwick and Durazo, 1985), the pheromone confusion technique (Baker et al., 1988), classical breeding or genetic engineering of insect-resistant plant cultivars (Trumble and Quiros, 1988), strip cropping or rotation (Power, 1988), intercropping (Letourneau, 1987), or improvement of "biorational" pesticides such as Bacillus thuringiensis through isolate selection or genetic engineering. Also under consideration are the concepts of managing pesticide resistance in vegetable crop systems through rotational programs that benefit the natural biological control agents and the use of new techniques for monitoring insecticide resistance levels in the field (Trumble, 1985; Sanderson et al., 1989). Probably the most striking development in the past few years is the degree to which these approaches are being integrated into management practices at the large-scale commercial production level.

\section{THE EXAMPLE OF CELERY}

Celery is an important agricultural commodity in California, with annual returns exceeding \$145 million on 8500 ha (California Celery Research Advisory Board, 1986). During the mid-to late 1970s, introduction of the phytophagous agromyzid, L. trifolii, began causing substantial economic losses (Trumble, 1981). In response to the loss of efficacy of many agricultural chemicals for leafminer control (Leibee, 1981), and the potential for rapid development of insecticide resistance (Keil and Parrella, 1983), interest increased in the development of a biological control or resistance management program that would maximize pest suppression while minimizing insecticide input.

The appeal of such a program was enhanced by reports that many insecticides were generating outbreaks of Liriomyza species. Hills and Taylor (1951) first documented this problem with reports that Liriomyza species populations [probably L. sativae (Blanchard)] 